\title{
Evaluation of charged particle induced reaction cross section data for production of the important therapeutic radionuclide ${ }^{186} \mathrm{Re}$
}

\author{
By M. Hussain ${ }^{1,2, *}$, S. Sudár ${ }^{2}$, M. N. Aslam ${ }^{1,2}$, A. A. Malik ${ }^{1}$, R. Ahmad ${ }^{1}$ and S. M. Qaim ${ }^{3}$ \\ ${ }^{1}$ Department of Physics, Government College University Lahore, Lahore 54000, Pakistan \\ 2 Institute of Experimental Physics, University of Debrecen, 4001 Debrecen, Hungary \\ ${ }^{3}$ Institut für Neurowissenschaften und Medizin, INM-5: Nuklearchemie, Forschungszentrum Jülich GmbH, 52425 Jülich, Germany
}

(Received June 8, 2009; accepted in final form February 18, 2010)

\author{
${ }^{186} \mathrm{Re} /$ Charged particle induced reaction / \\ Excitation function / Nuclear model calculation / \\ Data evaluation / Production yield calculation
}

\begin{abstract}
Summary. ${ }^{186} \mathrm{Re}$ is an important radionuclide having a halflife of $3.72 \mathrm{~d}$ that is suitable for radioimmunotherapy. Its production in no-carrier-added form is done via charged particle induced reactions and the data are available in EXFOR library. We evaluated two charged particle induced reactions, namely ${ }^{186} \mathrm{~W}(p, n){ }^{186} \mathrm{Re}$ and ${ }^{186} \mathrm{~W}(d, 2 n){ }^{186} \mathrm{Re}$. In the first case, analysis was done up to about $70 \mathrm{MeV}$ but in the latter only up to about $50 \mathrm{MeV}$. A statistical procedure supported by nuclear model calculations using the codes STAPRE, EMPIRE and TALYS was used to validate and fit the data. The recommended sets of data derived together with $95 \%$ confidence limits are reported. The application of those data, particularly in the calculation of integral yields is discussed. The ${ }^{186} \mathrm{~W}(p, n){ }^{186} \mathrm{Re}$ reaction on highly enriched ${ }^{186} \mathrm{~W}$ is presently the method of choice for production of no-carrier-added ${ }^{186} \mathrm{Re}$ and, taking into account the radionuclidic purity, the maximum recommended proton energy is $18 \mathrm{MeV}$. The formation of the very long-lived isomer, ${ }^{186 \mathrm{~m}} \mathrm{Re}$, is briefly discussed. The ${ }^{186} \mathrm{~W}(d, 2 n){ }^{186} \mathrm{Re}$ reaction could also be interesting if a high-intensity accelerator would be available.
\end{abstract}

\section{Introduction}

The significance of internal radionuclide therapy is increasing $(c f .[1,2])$, and the role of nuclear data in efficient production and application of suitable radionuclides has been discussed [3]. Although many radionuclides emitting corpuscular radiation have been in therapeutic use for a long time (for recent reviews $c f$. $[4,5]$ ), in recent years attention is being focused on Auger electron and $\alpha$-particle emitters, or low energy $\beta^{-}$-particle emitters. In this connection the radionuclide ${ }^{186} \mathrm{Re}$ is of considerable interest, firstly because of its suitable nuclear properties and secondly because of its chemical properties. It has a half-life of $3.72 \mathrm{~d}$ and decays to ${ }^{186} \mathrm{~W}$ and ${ }^{186} \mathrm{Os}$ by electron capture $(7.47 \%)$ and $\beta^{-}$-particle emission $(92.53 \%)$, respectively. The $E_{\beta \max }$ is $1.07 \mathrm{MeV}$. Furthermore, during the de-

\footnotetext{
*Author for correspondence (E-mail: mazharphd@yahoo.com).
}

cay a gamma ray of energy $137.2 \mathrm{keV}(9.49 \%)$ is emitted, which allows its use for in vivo tracking of the radiolabeled molecule to be able to perform dosimetric calculations. As far as the chemical properties are concerned, rhenium is a higher homologue of technetium which is known to form good chelates. Thus rhenium has been shown to form stable biphosphonate complex with hydroxyethylidene diphosphonate (HEDP) which has found many applications in breast and prostate cancer therapy $[4,6,7]$. Similarly ${ }^{186} \mathrm{Re}$ attached to bombesin demonstrated receptor-specific uptake in pancreas. Several other studies have also shown that ${ }^{186} \mathrm{Re}$ is an almost optimum radionuclide for radioimmunotherapy [5].

The radionuclide ${ }^{186} \mathrm{Re}$ has been produced using nuclear reactors via the ${ }^{185} \operatorname{Re}(n, \gamma){ }^{186} \operatorname{Re}$ reaction but not in no-carrier-added (nca) form, i.e. the specific activity is not very high $(c f .[8])$. Though the product may be acceptable for some human clinical trials, for radiolabelling of antibodies, high specific activity is needed. The nca ${ }^{186} \mathrm{Re}$ can be produced using cyclotrons $[8,9]$, and two major routes have been suggested. They are ${ }^{186} \mathrm{~W}(p, n){ }^{186} \mathrm{Re}$ and ${ }^{186} \mathrm{~W}(d, 2 n){ }^{186} \mathrm{Re}$. The $Q$-values and references to experimental data [10-31] are given in Table 1. In the present work we did a critical evaluation of the reaction cross section data for both the nuclear processes. For this purpose, nuclear model calculations were done using STAPRE, EMPIRE and TALYS.

A recent study on therapeutic radionuclides under the auspices of a Co-ordinated Research Project (CRP) of the IAEA $[10,11]$ has also dealt with the evaluation of cross sections of the same reactions leading to the formation of ${ }^{186} \mathrm{Re}$ in no-carrier-added form. The authors responsible for the evaluation of the production data of ${ }^{186} \mathrm{Re}$ in the CRP also reported their findings separately $[12,13,20]$. The present work is a more up to date evaluation; besides the older experimental data it considers several other relevant reports ( $c f .[23,53-55])$ that are not included in the CRP. Furthermore, the method of selection (and rejection) of data developed by us, and reported recently $[32,33]$, is better founded as compared to the rather empirical method used in the CRP. The nuclear model calculational codes STAPRE and TALYS were not previously used in the IAEA-CRP work. 
Table 1. Investigated nuclear processes for the production of ${ }^{186} \mathrm{Re}, Q$-values and references.

\begin{tabular}{|c|c|c|}
\hline Nuclear reaction & $\begin{array}{l}Q \text {-value } \\
(\mathrm{MeV})\end{array}$ & References \\
\hline${ }^{186} \mathrm{~W}(p, n){ }^{186} \operatorname{Re}$ & -1.3617 & $\begin{array}{l}\text { Shigeta et al. (1996) [16,17], Szelecsényi et al. (1997) [14], } \\
\text { Zhang et al. (1999) [18], Miah et al. (2002) [19], } \\
\text { Tárkányi et al. (2006) [12], Tárkányi et al. (2007) [20], } \\
\text { Lapi et al. (2007) [21], Menapace et al. (2007) [22,23], } \\
\text { Khandaker et al. (2008) [24] }\end{array}$ \\
\hline${ }^{186} \mathrm{~W}(d, 2 n){ }^{186} \mathrm{Re}$ & -3.5862 & $\begin{array}{l}\text { Pement, Wolke (1966) [25], Nassiff, Münzel (1973) [26], } \\
\text { Zhenlan et al. (1981) [27], Szelecsényi et al. (1999) [29], } \\
\text { Ishioka et al. (2002) [28], Tárkányi et al. (2003) [13], } \\
\text { Alekseev, Lazarev (2006) [30], Zhang et al. (2001) [31] }\end{array}$ \\
\hline
\end{tabular}

\section{Normalization of experimental data}

For each reaction, the data were normalized to $100 \%$ enrichment of ${ }^{186} \mathrm{~W}$, considering the given enrichment of the target or the isotopic composition of ${ }^{\text {nat }} \mathrm{W}$ i.e. ${ }^{180} \mathrm{~W}(0.12 \%)$, ${ }^{182} \mathrm{~W}(26.50 \%),{ }^{183} \mathrm{~W}(14.31 \%),{ }^{184} \mathrm{~W}(30.64 \%)$ and ${ }^{186} \mathrm{~W}$ $(28.43 \%)$. In the next step, the decay data used in each experiment were compared with the precise measurements of the gamma ray emission probabilities of ${ }^{186} \mathrm{Re}$ done by Miyahara et al. [15]. The correction factors were the same as described by Tárkányi et al. [20] and mentioned in the ongoing CRP of the IAEA [11]. Also in each case the normalization with respect to the monitor reaction cross section given in the report IAEA-TECDOC-1211 [34] was done.

\section{Method of data evaluation}

Some of the nuclear data evaluation methods use only the pure experimental data, like Ref. [34]; other evaluations take into account the results of the nuclear reaction model calculations [35] or are even mostly based on the model, e.g. JENDL 3.2 .

The idea in the present method is to use the model calculation in the evaluation process to improve the selection of the experimental data set and to make the interpolation and extrapolation in a theoretically correct way $(c f .[32,33])$. In the first step the cross sections were calculated by three nuclear reaction model codes (STAPRE, EMPIRE-II, TALYS), modifying the model parameters within their recommended ranges to get a quite good description of the experimental data. Then the experimental data were transformed to (approximately) incident energy independent data by calculating the ratio of the experimental data to the results of the model calculation. If the model calculations are done by varying the input parameters to get the best fit to the experimental data then the weighted average of the transformed data would be constant, i.e. equal to one. Since the real fitting procedure was not done by the model calculation, the transformed cross section data may have some energy dependence. Supposing that the evaluated cross section can be described as

$$
\sigma_{\mathrm{ev}}(E)=f(E) \sigma_{\text {model }}(E)
$$

where $\sigma_{\mathrm{ev}}(E), \sigma_{\text {model }}(E)$ and $f(E)$ are the evaluated cross section, model calculated cross section and the energy de- pendent normalization factor, respectively. It appears a good assumption that the $f(E)$ can be approximated with a polynomial function (instead of the constant). Usually a third order polynomial function was enough to describe the energy dependence. The polynomial fit is a well known procedure and besides fitted function, its confidence limits can be calculated. The ORIGIN code of OriginLab Corporation was used for the fitting procedure, which created the fitted $f(E)$ function, the confidence intervals for $f(E)$ and showed the quality of fitting (the figures below justify that the third order polynomial was enough).

We fitted the transformed cross sections using a polynomial function with weighting errors to estimate the energy dependent normalization factor. To estimate the best fit, we rejected the data that were far from the polynomial fit by more than three times their reported uncertainty. This means that the wrong data were rejected by objective criteria, and not empirically. Thereafter, again a polynomial fitting was done by taking into account the weighting factor of the uncertainties. The normalization factor for each model calculation was then estimated and multiplied by the model calculation to get the evaluated cross section. The $95 \%$ confidence limits obtained for the $f(E)$ were transformed back to cross section to estimate the uncertainty in the recommended data. The evaluation procedure was repeated with all the model calculations and the recommended sets of the data were generated by taking averages of the three normalized model calculations.

\section{Nuclear model calculations}

Several nuclear model calculational codes have been developed which are helpful in the evaluation of existing data; however, the adjustable parameters of the nuclear model code need to be fitted to reproduce the experimental data in the process of evaluation. We give a brief description of the three codes used in this work.

\subsection{Calculations using STAPRE}

This is one of the oldest codes and was developed by Uhl and Strohmaier [36]. It has been extensively used for data validation under Jülich-Debrecen collaboration (cf. $[37,38])$. The extensions to the original code refer to the exciton model and Hauser-Feshbach formula for gammarays in the exit channels. The preequilibrium emission was 
taken into account by the exciton model formalism while for compound emission the width fluctuation corrected HauserFeshbach formula was used. Direct interactions were not considered since their contributions were estimated to be $<10 \%$. The spherical optical model was used to produce the transmission coefficients of the particles; this was done by using the computer code SCAT 2 [39]. The optical model parameters used were the same as described earlier [33].

Primarily two particles and one hole approach was used for exciton model calculations to describe the precompound part; the details were the same as given earlier [33]. The levels were treated by the back-shifted Fermi gas model proposed by Dilg et al. [40]. The adopted levels for the excited states of product nuclei were described according to the data available in the form of ENDSF data files of Brookhaven National Laboratory, USA. For level density parameter the RIPL-2 [41] library of the IAEA was consulted and parameterization was also done according to the systematics of Egidy and Bucurescue [42]. The rigid body moment of inertia was used to account for the spin distribution of the level densities. The data for the spin and parities of the target nuclei and non-standard projectile were collected from the National Nuclear Data Center, Brookhaven National Laboratory, USA [43].

\subsection{Calculations using EMPIRE}

EMPIRE is a nuclear model code, developed by Herman et al. [44]. It is an empire of codes that work for different calculational tasks during a complete nuclear model calculation. We used the spherical optical model via the code ECIS03 [45] which calculates the elastic scattering and direct reactions induced by the light particles $A \leq 4$ in the frame of generalized optical model. It made use of the RIPL-2 library for optical model segment and for discrete levels. In all calculations the EMPIRE specific level density parameters were used; the pre-equilibrium modules used were the same as defined in the literature [44].

For protons incident on ${ }^{186} \mathrm{~W}$, the exciton model calculations were done with the code PCROSS [44]; cluster emission was considered in terms of the Iwamoto-Harada model [46] and the mean free path parameter in PCROSS was set to 1.8. The optical model parameters for emitted particles were set to RIPL-2. For deuterons incident on ${ }^{186} \mathrm{~W}$, the level density parameters were adjusted by the ATILNO [44] multiplier.

\subsection{Calculations using TALYS}

TALYS is a computer code system, developed by Koning et al. [47]. Some more details are given in the literature [48]. We described the use of this code earlier [33]. We adjusted the OM parameters. For protons incident on ${ }^{186} \mathrm{~W}$, rvadjust was set to 1.04 and avdadjust was taken to be 0.98 . For deuterons incident on ${ }^{186} \mathrm{~W}$, rvadjust was set to 1.2 . By default, in TALYS light ion emissions at higher energies were also considered. All parameterizations were done within the recommended ranges. All nuclei were considered nearly spherical in shape. The compound nucleus contribution was considered in the frame of Hauser-Feshbach model. The contributions of direct reactions were taken into account by DWBA. For level densities, the back-shifted Fermi gas model (BFM) was used, in which the pairing energy was taken as an adjustable parameter. Energy dependent shell effects were also considered.

\section{Evaluation of data for the ${ }^{186} \mathrm{~W}(p, n){ }^{186} \mathrm{Re}$ reaction}

Eight experiments were found in the literature and EXFOR library [49]. All measurements were done using ${ }^{\text {nat }} W$ as target material. All experimental data were normalized (see above). Shigeta et al. [16,17] reported 14 cross section values between 5 and $20 \mathrm{MeV}$. We introduced a normalization factor of 0.987 in all values. Flux monitoring was done using the ${ }^{65} \mathrm{Cu}(p, n)^{65} \mathrm{Zn}$ reaction and the data were taken from Collé et al. [50]. The data points at 9.59 and $10.8 \mathrm{MeV}$ showed large deviation.

Zhang et al. [18] reported eight cross section values between 7 and $18 \mathrm{MeV}$. The beam monitor reactions used were the ${ }^{63} \mathrm{Cu}(p, 2 n)^{62} \mathrm{Zn}$ and ${ }^{65} \mathrm{Cu}(p, n)^{65} \mathrm{Zn}$ processes and the data were taken from Grütter [51]. The data were normalized by multiplying with 1.15 for the monitor reaction, ${ }^{63} \mathrm{Cu}(p, 2 n)^{62} \mathrm{Zn}$; and for the new decay data a multiplication factor of 1.434 was used. The uncertainty in data was estimated to be $8-10 \%$.

Miah et al. [19] measured the cross section of this reaction in the energy region above $50 \mathrm{MeV}$. Their data were helpful in studying the tail of the pre-equilibrium part of the excitation function up to $70 \mathrm{MeV}$. The data of the beam monitor reaction ${ }^{27} \mathrm{Al}(p, x)^{22} \mathrm{Na}$ [52] and the decay data used were compared with the latest standards for normalization of the experimental values. A normalization factor of 0.971 was applied.

Several reports on data for the production of ${ }^{186} \mathrm{Re}$ via the ${ }^{186} \mathrm{~W}(p, n){ }^{186} \mathrm{Re}$ reaction have appeared under a DebrecenBrussels collaboration $[12,14,20]$. The preliminary data of Szelecsényi et al. [14] were reported in detail by Tárkányi et al. [12]. Later, those data were corrected by the authors, and some new measurements were also done [20]. The model calculations utilizing the codes ALICE-IPPE, GNASH and EMPIRE-II reproduced the experimental data to some extent up to $10 \mathrm{MeV}$ [20] but showed a higher trend in cross section values at higher energies.

Lapi et al. [21] reported cross sections for this reaction from 6.5 to $17.6 \mathrm{MeV}$. Measurements were done at three places, namely Edmonton, BNL and TRIUMF. Their data were close to the results of Shigeta et al. $[16,17]$ except for the peak values around $10 \mathrm{MeV}$ where the latter values are exceptionally high (as mentioned above). The experimental data also showed good agreement with EMPIRE calculations. Menapace et al. [22,23] measured cross sections up to about $17 \mathrm{MeV}$. The normalization factor introduced in our work for those data was 0.868 . The normalized data were about $5 \%$ lower than the nuclear model calculations while the general trend of the excitation function followed the nuclear theory. Recently, Khandaker et al. [24] reported data for the same reaction up to $40 \mathrm{MeV}$. The estimated uncertainties were between 8 and 14\%. The decay parameters and monitor reaction reference were found to be in good agreement with the latest accepted values. They performed nu- 


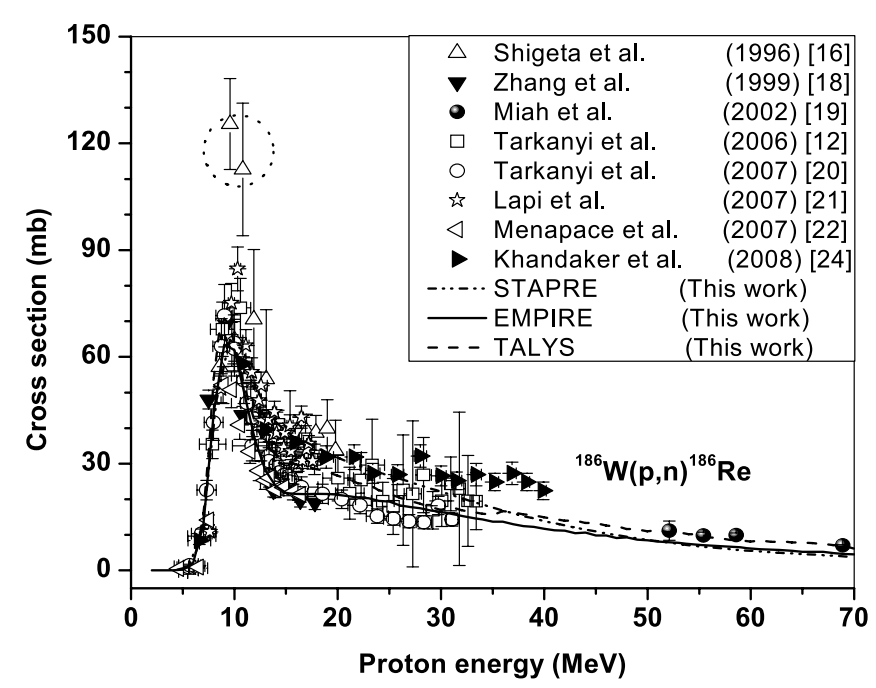

Fig. 1. Normalized experimental data and results of nuclear model calculations for the ${ }^{186} \mathrm{~W}(p, n)^{186} \mathrm{Re}$ reaction; the encircled data points were neglected.

clear model calculations using the codes ALICE-IPPE and TALYS. Whereas ALICE-IPPE gave very discrepant values, the results of TALYS agreed with the experimental data up to about $15 \mathrm{MeV}$ but not beyond that energy.

The normalized cross section values from all the eight experiments discussed above are plotted in Fig. 1. The theoretical calculations using the codes STAPRE, EMPIRE and TALYS reproduced the experimental data very well. The two data points by Shigeta et al. [16,17] were not reproduced by the theory. The statistical approach adopted using polynomial fitting of the cross section ratios (measured/ model calculations) as mentioned above, gave results which are shown in Figs. 2, 3 and 4. On the basis of those results the two data points by Shigeta et al. $[16,17]$ were neglected. All the other data points were fitted and the recommended curve is given in Fig. 5 together with 95\% confidence limits. The recommended numerical values are presented in Table 2. We compared our recommended cross section values with the data of the ongoing CRP in three critical regions. Below $10 \mathrm{MeV}$ our values are $10-15 \%$ lower, above $10 \mathrm{MeV}$ up to $30 \mathrm{MeV}$ they are 5-10\% higher, and above $30 \mathrm{MeV}$ the values are about 15\% higher than the CRP data.

\section{Evaluation of data for the ${ }^{186} \mathrm{~W}(d, 2 n){ }^{186} \mathrm{Re}$ reaction}

Six experiments were found in the literature for this reaction (for references see Table 1). Pement and Wolke [25] reported nine cross section values between 5.9 and $14 \mathrm{MeV}$ using $97.2 \%$ enriched ${ }^{186} \mathrm{~W}$ as target material. The data were normalized by 1.028 as a multiplier. A consistency was found in the excitation function except for values at the lowest energies. Nassiff and Münzel [26] reported six data points from 7.3 to $16.7 \mathrm{MeV}$. The status of monitor reaction ${ }^{27} \mathrm{Al}(d, \alpha p){ }^{24} \mathrm{Na}$ was good, since it has a difference of

Table 2. Recommended cross section data for the ${ }^{186} \mathrm{~W}(p, n)^{186}$ Re reaction.

\begin{tabular}{|c|c|c|c|c|c|c|c|}
\hline \multirow{2}{*}{$\begin{array}{l}\text { Energy } \\
(\mathrm{MeV})\end{array}$} & \multirow{2}{*}{$\begin{array}{c}\sigma \\
(\mathrm{mb})\end{array}$} & \multicolumn{2}{|c|}{$95 \%$ confidence limits } & \multirow{2}{*}{$\begin{array}{c}\text { Energy } \\
(\mathrm{MeV})\end{array}$} & \multirow{2}{*}{$\begin{array}{c}\sigma \\
(\mathrm{mb})\end{array}$} & \multicolumn{2}{|c|}{$95 \%$ confidence limits } \\
\hline & & lower & upper & & & lower & upper \\
\hline 5.0 & 0.35 & 0.29 & 0.40 & 21.0 & 26.0 & 24.1 & 27.8 \\
\hline 5.5 & 0.96 & 0.82 & 1.11 & 22.0 & 25.3 & 23.4 & 27.2 \\
\hline 6.0 & 3.0 & 2.6 & 3.4 & 23.0 & 24.8 & 22.9 & 26.7 \\
\hline 6.5 & 7.3 & 6.4 & 8.2 & 24.0 & 24.1 & 22.2 & 26.0 \\
\hline 7.0 & 13.6 & 12.1 & 15.2 & 25.0 & 23.6 & 21.7 & 25.6 \\
\hline 7.5 & 28.2 & 25.3 & 31.1 & 26.0 & 22.7 & 20.8 & 24.7 \\
\hline 8.0 & 44.2 & 39.9 & 48.4 & 27.0 & 22.1 & 20.1 & 24.1 \\
\hline 8.5 & 54.3 & 49.4 & 59.1 & 28.0 & 21.6 & 19.6 & 23.7 \\
\hline 9.0 & 61.1 & 56.2 & 66.1 & 29.0 & 21.0 & 18.9 & 23.1 \\
\hline 9.5 & 62.6 & 57.9 & 67.2 & 30.0 & 20.4 & 18.3 & 22.5 \\
\hline 10.0 & 60.8 & 56.7 & 64.8 & 32.0 & 19.7 & 17.4 & 22.0 \\
\hline 10.5 & 56.2 & 52.8 & 59.6 & 34.0 & 18.7 & 16.3 & 21.1 \\
\hline 11.0 & 51.7 & 48.7 & 54.7 & 36.0 & 18.4 & 15.9 & 21.0 \\
\hline 11.5 & 46.7 & 44.1 & 49.3 & 38.0 & 17.3 & 14.7 & 19.9 \\
\hline 12.0 & 41.9 & 39.6 & 44.3 & 40.0 & 16.4 & 13.7 & 19.1 \\
\hline 12.5 & 38.3 & 36.2 & 40.4 & 42.0 & 15.5 & 12.8 & 18.2 \\
\hline 13.0 & 35.1 & 33.2 & 37.0 & 44.0 & 14.7 & 12.1 & 17.4 \\
\hline 13.5 & 32.9 & 31.1 & 34.6 & 46.0 & 13.9 & 11.3 & 16.4 \\
\hline 14.0 & 31.2 & 29.6 & 32.9 & 48.0 & 13.0 & 10.5 & 15.4 \\
\hline 14.5 & 30.1 & 28.5 & 31.7 & 50.0 & 12.2 & 9.8 & 14.5 \\
\hline 15.0 & 29.2 & 27.7 & 30.8 & 52.0 & 11.5 & 9.3 & 13.7 \\
\hline 15.5 & 28.9 & 27.3 & 30.5 & 54.0 & 10.9 & 8.8 & 12.9 \\
\hline 16.0 & 28.5 & 26.9 & 30.1 & 56.0 & 10.1 & 8.2 & 12.0 \\
\hline 16.5 & 28.3 & 26.6 & 29.9 & 58.0 & 9.5 & 7.7 & 11.2 \\
\hline 17.0 & 28.1 & 26.4 & 29.7 & 60.0 & 8.9 & 7.3 & 10.6 \\
\hline 17.5 & 27.8 & 26.1 & 29.5 & 62.0 & 8.6 & 6.9 & 10.2 \\
\hline 18.0 & 27.6 & 25.9 & 29.3 & 64.0 & 8.2 & 6.5 & 9.9 \\
\hline 18.5 & 27.4 & 25.6 & 29.1 & 66.0 & 7.9 & 6.1 & 9.7 \\
\hline 19.0 & 27.1 & 25.3 & 28.9 & 68.0 & 7.4 & 5.4 & 9.4 \\
\hline 19.5 & 26.9 & 25.1 & 28.7 & 70.0 & 6.8 & 4.7 & 8.9 \\
\hline 20.0 & 26.6 & 24.7 & 28.4 & & & & \\
\hline
\end{tabular}



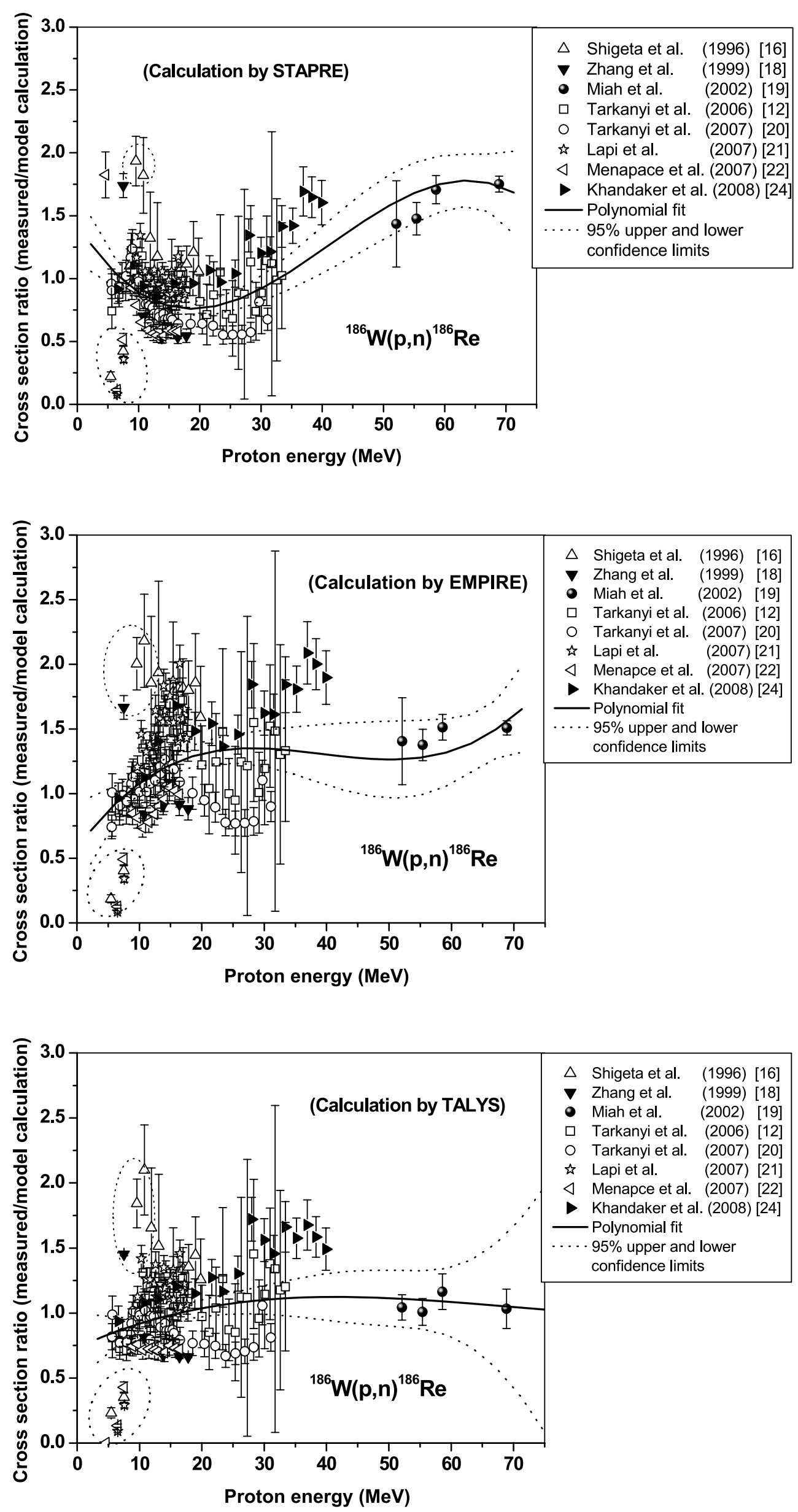

Fig. 2. Ratios of experimental cross section to calculated cross section by STAPRE, plotted as a function of proton energy.

Fig. 3. Ratios of experimental cross section to calculated cross section by EMPIRE, plotted as a function of proton energy.

Fig. 4. Ratios of experimental cross section to calculated cross section by TALYS, plotted as a function of proton energy. 


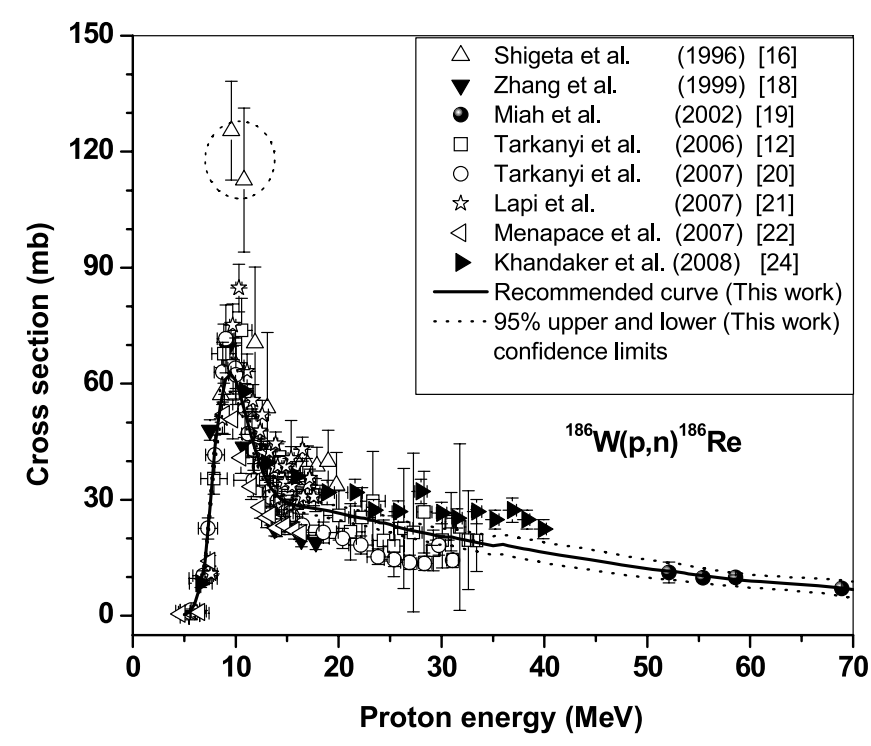

Fig. 5. Recommended cross section curve with $95 \%$ upper and lower confidence limits for the ${ }^{186} \mathrm{~W}(p, n){ }^{186} \mathrm{Re}$ reaction.

only $5 \%$ in cross section values when compared with the recommended cross section values in the IAEA-TECDOC1211 [34]. The data were higher than those reported by all other authors in the energy region between 10 and $20 \mathrm{MeV}$. Zhenlan et al. [27] reported ten data points in the deuteron energy range of 7.0 to $15.7 \mathrm{MeV}$. The excitation function has a peak around $12 \mathrm{MeV}$. The data are consistent with Pement and Wolke [25] but at energies above $12 \mathrm{MeV}$ there is a shift of $1 \mathrm{MeV}$ to lower energies in comparison with the other data. Ishioka et al. [28] reported 17 data points up to $34 \mathrm{MeV}$. The measured excitation function is consistent except for somewhat high values around the peak at $12.4 \mathrm{MeV}$ as well as at $25.0 \mathrm{MeV}$. Tárkányi et al. [13] measured the excitation function up to $50 \mathrm{MeV}$ in detail. The ${ }^{27} \mathrm{Al}(d, x)^{22} \mathrm{Na}$ and ${ }^{27} \mathrm{Al}(d, x)^{24} \mathrm{Na}$ monitor reactions were used with a good status of reaction cross sections. The uncertainty in the absolute cross section values was $12 \%$; near the threshold it was about 20\%. Alekseev and Lazarev [30] reported the data up to $12 \mathrm{MeV}$. They used the standard reference for the monitor reaction cross sections. Their data were about $10 \%$ higher than the general trend.

The normalized cross section data are shown in Fig. 6 together with the results of theoretical calculations using the codes STAPRE, EMPIRE and TALYS. Whereas the results of STAPRE and TALYS calculations reproduce the experimental data very well, the calculations by EMPIRE over predict the experimental data up to about $25 \mathrm{MeV}$ but slightly underestimate the cross section above $40 \mathrm{MeV}$. The overall shape of the excitation function was, however, the same for all the three model calculations.

In order to select the data, the statistical approach using the polynomial fitting of the ratio data (measured/model calculation), as mentioned above for the ${ }^{186} \mathrm{~W}(p, n){ }^{186} \mathrm{Re}$ reaction, was adopted. The polynomial fitting of the ratio data are shown in Figs. 7, 8 and 9. The ratio calculations for the TALYS are good while for STAPRE and EMPIRE, they are higher in the energy region above $40 \mathrm{MeV}$. The cross sections at the pre-equilibrium tail of the excitation function are very low; so in absolute terms the deviation in the high energy region does not mean much. But in the low energy region the

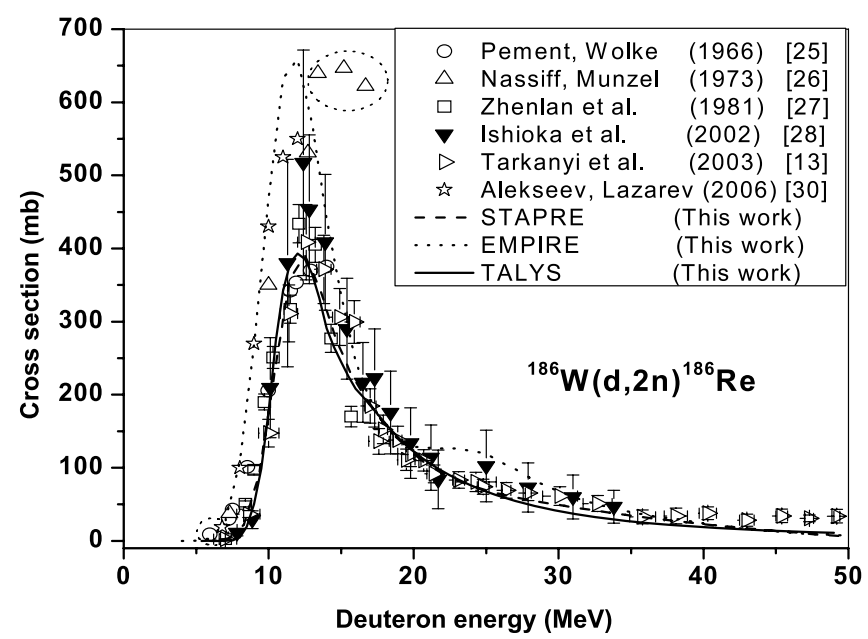

Fig. 6. Normalized experimental data and results of nuclear model calculations for the ${ }^{186} \mathrm{~W}(d, 2 n)^{186} \mathrm{Re}$ reaction; the encircled data points were neglected.

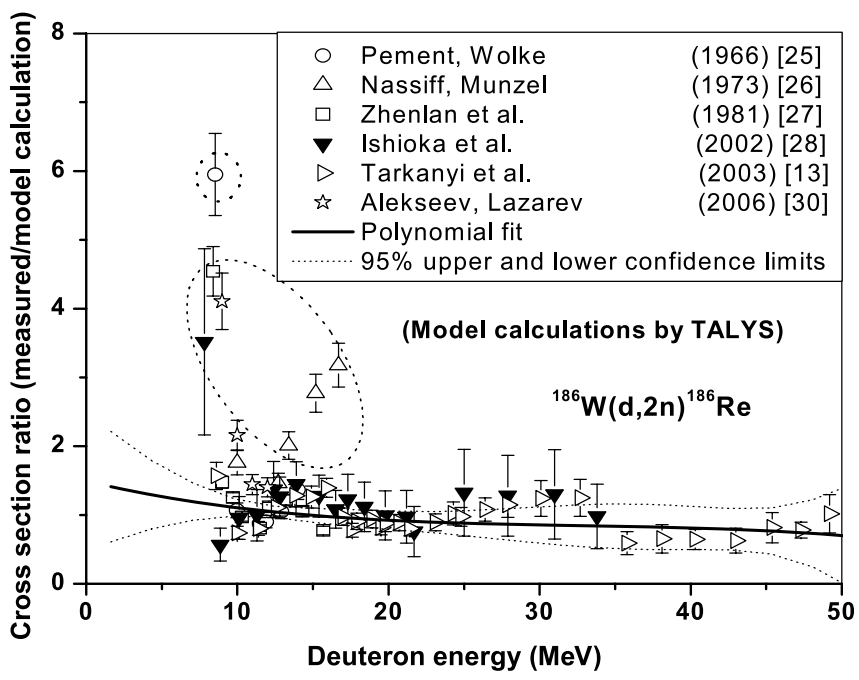

Fig. 7. Ratios of experimental cross section to calculated cross section by TALYS for the ${ }^{186} \mathrm{~W}(d, 2 n){ }^{186} \mathrm{Re}$ reaction, plotted as a function of deuteron energy.

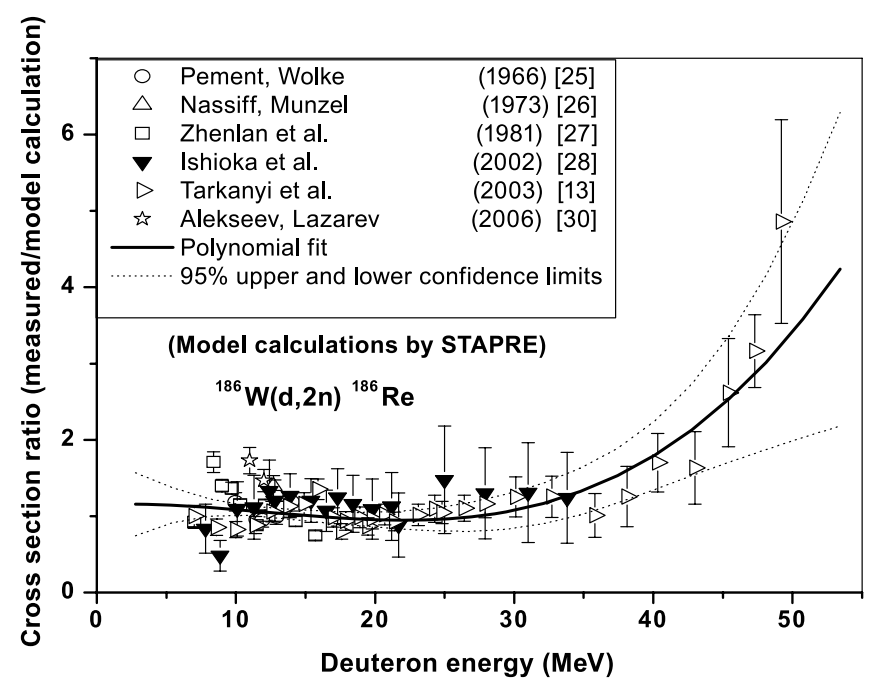

Fig. 8. Ratios of experimental cross section to calculated cross section by STAPRE for the ${ }^{186} \mathrm{~W}(d, 2 n)^{186}$ Re reaction, plotted as a function of deuteron energy. 


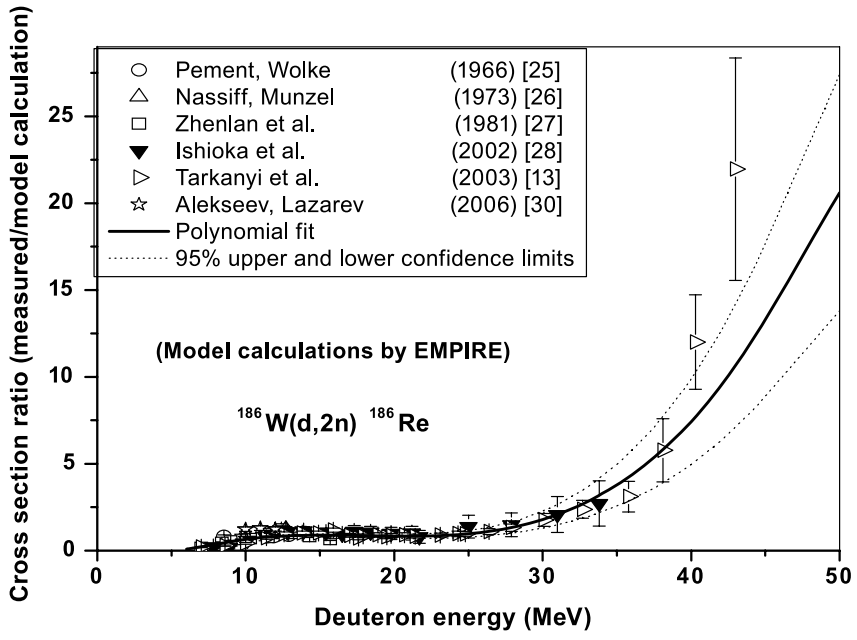

Fig. 9. Ratios of experimental cross section to calculated cross section by EMPIRE for the ${ }^{186} \mathrm{~W}(d, 2 n){ }^{186} \mathrm{Re}$ reaction, plotted as a function of deuteron energy.

deviation shows the weakness in the experimental data. The $3 \sigma$ limit was selected to discard the data and on that basis most of the data by Nassiff and Münzel [26] and the lower most values by Pement and Wolke [25] were neglected. All the other data points were fitted and the recommended curve with $95 \%$ confidence limits is given in Fig. 10. The recom-

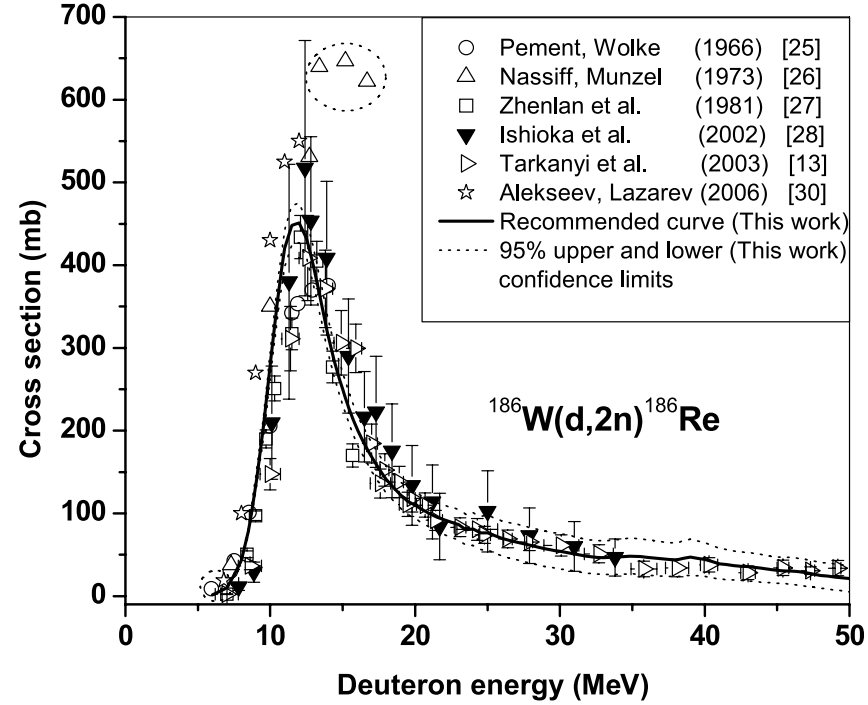

Fig. 10. Recommended cross section curve with $95 \%$ upper and lower confidence limits for the ${ }^{186} \mathrm{~W}(d, 2 n)^{186} \mathrm{Re}$ reaction.

mended numerical values are presented in Table 3. We compared the recommended values of this work with the data of the ongoing CRP of the IAEA. Up to $12 \mathrm{MeV}$, our recommended cross sections are 5-10\% higher and above $12 \mathrm{MeV}$ they are about $5 \%$ lower than the CRP values.

Table 3. Recommended cross section data for the ${ }^{186} \mathrm{~W}(d, 2 n){ }^{186} \mathrm{Re}$ reaction.

\begin{tabular}{|c|c|c|c|c|c|c|c|}
\hline \multirow{2}{*}{$\begin{array}{l}\text { Energy } \\
(\mathrm{MeV})\end{array}$} & \multirow{2}{*}{$\begin{array}{c}\sigma \\
(\mathrm{mb})\end{array}$} & \multicolumn{2}{|c|}{$95 \%$ confidence limits } & \multirow{2}{*}{$\begin{array}{c}\text { Energy } \\
(\mathrm{MeV})\end{array}$} & \multirow{2}{*}{$\begin{array}{c}\sigma \\
(\mathrm{mb})\end{array}$} & \multicolumn{2}{|c|}{$95 \%$ confidence limits } \\
\hline & & lower & upper & & & lower & upper \\
\hline 6.0 & 1.37 & 1.26 & 1.47 & 22.0 & 92.1 & 74.7 & 109.6 \\
\hline 6.5 & 5.77 & 5.38 & 6.15 & 22.5 & 89.2 & 71.1 & 107.3 \\
\hline 7.0 & 10.4 & 9.7 & 11.1 & 23.0 & 86.4 & 67.7 & 105.1 \\
\hline 7.5 & 25.9 & 24.4 & 27.4 & 23.5 & 80.3 & 61.7 & 98.9 \\
\hline 8.0 & 43.7 & 41.2 & 46.2 & 24.0 & 80.9 & 61.1 & 100.7 \\
\hline 8.5 & 78.3 & 74.1 & 82.4 & 24.5 & 76.4 & 56.4 & 96.4 \\
\hline 9.0 & 134.6 & 126.1 & 143.2 & 25.0 & 76.7 & 55.6 & 97.8 \\
\hline 9.5 & 198.2 & 186.5 & 209.9 & 25.5 & 73.2 & 52.1 & 94.4 \\
\hline 10.0 & 277.9 & 262.4 & 293.4 & 26.0 & 69.8 & 48.6 & 90.9 \\
\hline 10.5 & 356.7 & 337.0 & 376.4 & 26.5 & 67.6 & 46.2 & 89.0 \\
\hline 11.0 & 420.5 & 398.4 & 442.6 & 27.0 & 65.5 & 43.9 & 87.1 \\
\hline 11.5 & 448.2 & 424.2 & 472.1 & 27.5 & 63.3 & 41.7 & 84.9 \\
\hline 12.0 & 451.3 & 427.4 & 475.2 & 28.0 & 61.1 & 39.6 & 82.7 \\
\hline 12.5 & 432.4 & 409.4 & 455.4 & 28.5 & 59.1 & 37.7 & 80.6 \\
\hline 13.0 & 397.8 & 375.4 & 420.2 & 29.0 & 57.2 & 35.9 & 78.5 \\
\hline 13.5 & 357.3 & 335.7 & 379.0 & 29.5 & 55.7 & 34.4 & 77.1 \\
\hline 14.0 & 313.8 & 293.1 & 334.5 & 30.0 & 54.4 & 33.1 & 75.7 \\
\hline 14.5 & 280.0 & 260.1 & 300.0 & 31.0 & 51.1 & 30.3 & 72.0 \\
\hline 15.0 & 250.5 & 231.0 & 270.0 & 32.0 & 47.8 & 27.5 & 68.0 \\
\hline 15.5 & 224.4 & 205.7 & 243.1 & 33.0 & 46.5 & 26.2 & 66.7 \\
\hline 16.0 & 201.3 & 183.3 & 219.3 & 34.0 & 47.3 & 26.4 & 68.2 \\
\hline 16.5 & 184.3 & 166.7 & 201.9 & 35.0 & 48.7 & 26.9 & 70.4 \\
\hline 17.0 & 168.0 & 150.8 & 185.3 & 36.0 & 46.9 & 25.5 & 68.2 \\
\hline 17.5 & 154.3 & 137.5 & 171.0 & 37.0 & 45.0 & 24.3 & 65.8 \\
\hline 18.0 & 141.2 & 124.9 & 157.4 & 38.0 & 43.8 & 23.3 & 64.3 \\
\hline 18.5 & 131.3 & 115.4 & 147.3 & 39.0 & 47.1 & 25.3 & 68.9 \\
\hline 19.0 & 122.1 & 106.4 & 137.8 & 40.0 & 44.2 & 23.7 & 64.7 \\
\hline 19.5 & 114.6 & 98.9 & 130.4 & 42.0 & 37.1 & 19.6 & 54.6 \\
\hline 20.0 & 109.8 & 93.8 & 125.8 & 44.0 & 33.5 & 17.0 & 50.0 \\
\hline 20.5 & 104.4 & 88.2 & 120.7 & 46.0 & 30.5 & 14.3 & 46.8 \\
\hline 21.0 & 99.5 & 83.0 & 115.9 & 48.0 & 25.2 & 9.7 & 40.7 \\
\hline 21.5 & 95.6 & 78.7 & 112.6 & 50.0 & 21.2 & 5.3 & 37.0 \\
\hline
\end{tabular}




\section{Application of evaluated data}

\subsection{Calculation of integral yields}

A critical evaluation of the available experimental information on the excitation functions of the reactions ${ }^{186} \mathrm{~W}(p, n){ }^{186} \mathrm{Re}$ and ${ }^{186} \mathrm{~W}(d, 2 n){ }^{186} \mathrm{Re}$, and their validation using several nuclear model calculational codes, has led to recommended cross section data for those reactions. Those data could now be confidently used for calculation of integral yield of ${ }^{186} \mathrm{Re}$ via a given reaction over a certain energy range. We give the calculated yields for the two reactions in Figs. 11 and 12, together with the 95\% confidence limits. In general, these yield values should be more accurate than the ones reported by authors from their own individual measurements.

The calculated integral yields of this work were compared with the recommended yields of the ongoing CRP of the IAEA. The yield deduced from the evaluated curve for the ${ }^{186} \mathrm{~W}(p, n){ }^{186} \mathrm{Re}$ reaction presented in this work is $12.4 \mathrm{MBq} / \mu \mathrm{A} \mathrm{h}$ at $40 \mathrm{MeV}$. This value is about $10 \%$ higher than the IAEA-CRP value [11]. But if we take into account the $95 \%$ confidence limits, the difference is only about $3 \%$ with the lower confidence limit. The yield values were also compared with the data of Dmitriev and Molin [53] and

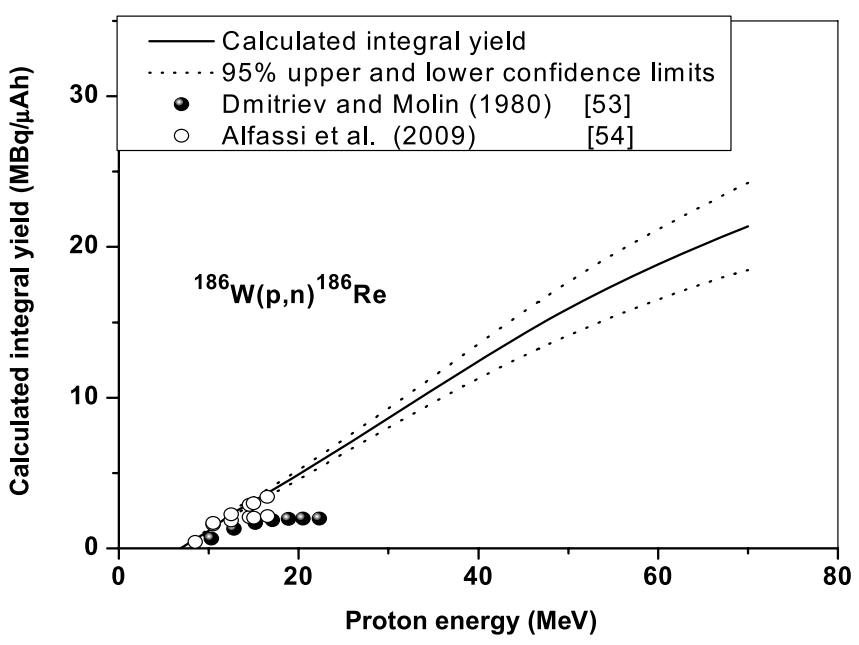

Fig. 11. Calculated integral yield of ${ }^{186} \mathrm{Re}$ via the ${ }^{186} \mathrm{~W}(p, n)^{186} \mathrm{Re}$ reaction.

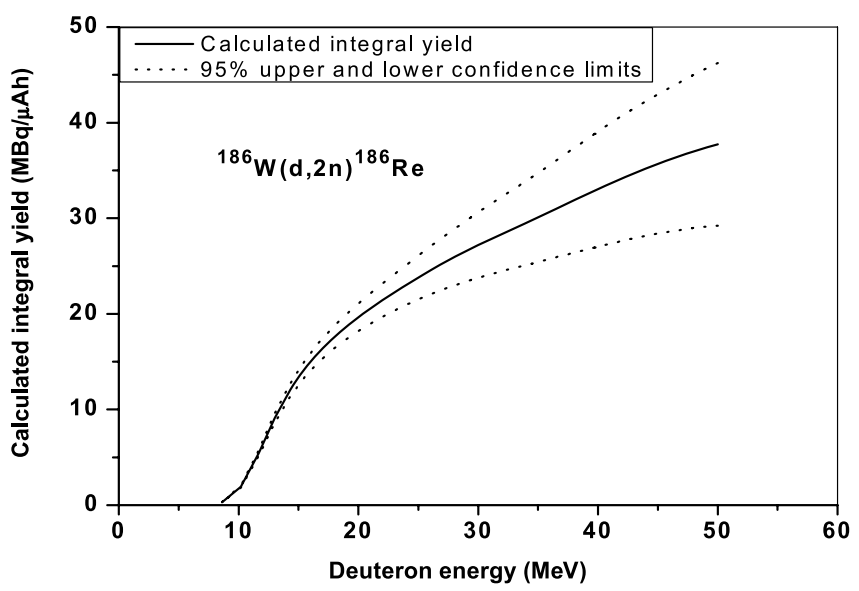

Fig. 12. Calculated integral yield of ${ }^{186} \mathrm{Re}$ via the ${ }^{186} \mathrm{~W}(d, 2 n)^{186} \mathrm{Re}$ reaction. with Alfassi et al. [54], their values agree with calculated yields up to $15 \mathrm{MeV}$. Similarly, for the ${ }^{186} \mathrm{~W}(d, 2 n){ }^{186} \mathrm{Re}$ reaction our calculated integral yield was compared with the earlier reported yields of Zhang et al. [31] and Solin et al. [55] as well as with the IAEA-CRP value. The calculated integral yield from our recommended curve amounts to $8.5 \mathrm{MBq} / \mu \mathrm{Ah}$ at $12.8 \mathrm{MeV}, 15.0 \mathrm{MBq} / \mu \mathrm{A} \mathrm{h}$ at $16 \mathrm{MeV}$ and $33.1 \mathrm{MBq} / \mu \mathrm{A} \mathrm{h}$ at $40 \mathrm{MeV}$. These values are about $20 \%$ lower than the reported yields of Zhang et al. [31] and Solin et al. [55], respectively, and 6\% higher than the yield of the IAEA-CRP [11]. It should, however, be noted that the CRP recommended yield is within the $95 \%$ confidence limits of the calculated integral yield of this work.

\subsection{Choice of production route and achievable batch yield}

An overall comparison of the yields from the two reactions studied shows that, for the same energy range, the ${ }^{186} \mathrm{~W}(d, 2 n){ }^{186} \mathrm{Re}$ reaction gives much higher yield than the ${ }^{186} \mathrm{~W}(p, n){ }^{186} \mathrm{Re}$ reaction (as mentioned earlier in Refs. $[12,13])$. Nonetheless, presently the reaction ${ }^{186} \mathrm{~W}(p, n)^{186} \mathrm{Re}$ is favoured due to two reasons. Firstly, the available commercial production cyclotrons have deuteron energy only half of the proton energy (e.g. $18 \mathrm{MeV} p / 9 \mathrm{MeV} d ; 30 \mathrm{MeV}$ $p / 15 \mathrm{MeV} d$ ) so that the achievable ${ }^{186} \mathrm{Re}$ yield via the $(d, 2 n)$ reaction is considerably smaller. Secondly, proton beams of much higher intensity are available than the deuteron beams. Thus presently the method of choice is the ${ }^{186} \mathrm{~W}(p, n)^{186} \mathrm{Re}$ reaction. If, however, higher energy and higher intensity deuteron beams could be made available, the ${ }^{186} \mathrm{~W}(d, 2 n){ }^{186} \mathrm{Re}$ reaction would also become important.

From the point of view of radionuclidic purity of ${ }^{186} \mathrm{Re}$, the use of highly enriched ${ }^{186} \mathrm{~W}$ target for production is mandatory. Whereas the cross section work was done using ${ }^{\text {nat }} \mathrm{W}$, for production purposes a high-enrichment of ${ }^{186} \mathrm{~W}$ is absolutely necessary. It needs also to be emphasized that the maximum recommended proton energy is $18 \mathrm{MeV}$, although the yield of ${ }^{186} \mathrm{Re}$ is further increasing. Beyond $18 \mathrm{MeV}$, even while using highly enriched ${ }^{186} \mathrm{~W}$ as target material, the amount of ${ }^{184 \mathrm{~g}} \operatorname{Re}\left(T_{1 / 2}=38.0 \mathrm{~d}\right)$ formed via the ${ }^{186} \mathrm{~W}(p, 3 n)$-reaction ( $Q$-value $\left.=-15.2 \mathrm{MeV}\right)$ would be appreciable [cf. 12], thereby introducing a radionuclidic impurity in ${ }^{186} \mathrm{Re}$. Besides the ${ }^{186} \mathrm{~W}(p, n){ }^{186} \mathrm{Re}$ reaction discussed above, excitation functions of the ${ }^{186} \mathrm{~W}(p, 2 n)^{185} \mathrm{Re}$ and ${ }^{186} \mathrm{~W}(p, 3 n)^{184 \mathrm{~m}+\mathrm{g}} \mathrm{Re}$ reactions were also calculated using the code TALYS. From the obtained curves the levels of the impurities ${ }^{184 \mathrm{~m}+\mathrm{g}} \mathrm{Re}$ (radioactive) and ${ }^{185} \mathrm{Re}$ (stable) produced with ${ }^{186} \mathrm{Re}$ at various energies were estimated. At $18 \mathrm{MeV}$ the level of ${ }^{184 \mathrm{~m}+\mathrm{g}} \mathrm{Re}$ in ${ }^{186} \mathrm{Re}$ was $<4 \%$, at $20 \mathrm{MeV}$ about $30 \%$ and at $23 \mathrm{MeV}$ it increased to about $80 \%$. Thus the maximum energy for production is suggested as $18 \mathrm{MeV}$. The calculated amount of ${ }^{185} \mathrm{Re}$ (stable) was $3.28 \times 10^{13}$ atoms $/ \mu \mathrm{A} h$. It is also worth pointing out that a lower enrichment of ${ }^{186} \mathrm{~W}$ would lead to lower yield of ${ }^{186} \mathrm{Re}$ and at the same time higher level of impurity (formed via reactions on isotopes of tungsten other than $\left.{ }^{186} \mathrm{~W}\right)$.

It should be mentioned that the ${ }^{186} \mathrm{~W}(p, n)^{186} \mathrm{Re}$ reaction is intrinsically a low-yield process and the projected batch yield using $18 \mathrm{MeV}$ protons, $5 \mu \mathrm{A}, 24 \mathrm{~h}$ irradiation, amounts to about $0.5 \mathrm{GBq}$ [21]. The development of high-current target, capable of withstanding beam currents of $300 \mu \mathrm{A}$ could 
increase the yield possibly up to about $30 \mathrm{GBq}$. This would be a sufficient amount for many applications but it would not reach the level achieved in case of ${ }^{67} \mathrm{Ga}\left(T_{1 / 2}=3.26 \mathrm{~d}\right)$ or ${ }^{111}$ In $\left(T_{1 / 2}=2.8 \mathrm{~d}\right)$, which are widely distributed and used. Thus the cyclotron production of ${ }^{186} \mathrm{Re}$ would lead to radionuclidically pure product but possibly not in large supplies. Though the product would be in no-carrier-added form, the specific radioactivity of ${ }^{186} \mathrm{Re}$ would partly depend upon the amount of stable ${ }^{185} \mathrm{Re}$ formed. Under the above production conditions (leading to $30 \mathrm{GBq}$ of ${ }^{186} \mathrm{Re}$ ) the calculated number of ${ }^{185} \mathrm{Re}$ nuclei formed would amount to $2.36 \times 10^{17}$, corresponding to about $70 \mu \mathrm{g}$ of ${ }^{185} \mathrm{Re}$. The specific radioactivity of ${ }^{186} \mathrm{Re}$ would then be approximately $71 \mathrm{GBq} / \mu \mathrm{mol}$. This is not a very high value. Thus a shorter irradiation or lowering the proton energy to about $15 \mathrm{MeV}$ (to decrease the amount of ${ }^{185} \mathrm{Re}$ formed) would be preferable.

An analysis of the ${ }^{186} \mathrm{~W}(d, 2 n)^{186} \mathrm{Re}$ process similar to that for the ${ }^{186} \mathrm{~W}(p, n)^{186} \mathrm{Re}$ reaction, by performing TALYS calculations on ${ }^{186} \mathrm{~W}(d, x n)$ reactions, showed that the maximum deuteron energy used should be $20 \mathrm{MeV}$. The yield of ${ }^{186} \mathrm{Re}$ at this energy is about four times higher than that via the $(p, n)$ reaction at $18 \mathrm{MeV}$, the level of the radioactive ${ }_{184 \mathrm{~m}, \mathrm{~g}} \mathrm{Re}$ impurity would be comparable, and the amount of stable ${ }^{185} \mathrm{Re}$ formed would be about $55 \%$ of the value associated with the $(p, n)$ process. The specific activity of ${ }^{186} \mathrm{Re}$ would thus be higher. The development and use of a high intensity deuteron accelerator thus appears to be very advantageous. Even a $15 \mathrm{MeV}$ high current deuteron beam would be of great value.

\section{Long-lived isomeric impurity ${ }^{186 m} \mathrm{Re}$}

Rhenium-186 has two isomeric states; namely, the ground state ${ }^{186 g} \operatorname{Re}\left(T_{1 / 2}=3.72 \mathrm{~d}\right)$ with a spin $\left(1^{-}\right)$and a longlived metastable state ${ }^{186 \mathrm{~m}} \operatorname{Re}\left(T_{1 / 2}=2 \times 10^{5} \mathrm{y}\right)$ lying at about $150 \mathrm{keV}$ above the ground state and having a spin of $\left(8^{+}\right)$. In studies related to production of ${ }^{186 g} \mathrm{Re}$, so far almost no attention has been paid to ${ }^{186 \mathrm{~m}} \mathrm{Re}$. We calculated cross sections for the formation of the isomeric state using the code EMPIRE 3.0. Furthermore, we developed the ratio $\left(\sigma_{\mathrm{m}} / \sigma_{\mathrm{g}}\right)$ for the ${ }^{186} \mathrm{~W}(p, n)^{186 m, g} \mathrm{Re}$ reaction which is shown in Fig. 13 as a function of proton energy. The values were compared with the results published in [20]. An agreement within about $5 \%$ was observed. Evidently the ratio is small at low energies but increases rapidly with the increasing proton energy, reaching a maximum of about 0.18 at $13 \mathrm{MeV}$ and then, remaining almost constant at higher energies.

It was considered worthwhile to estimate the level of the long-lived impurity ${ }^{186 \mathrm{~m}} \mathrm{Re}$ in the desired product ${ }^{186} \mathrm{Re}$, both for reactor and cyclotron production. Evidently, the ratio of the activities $\left(Y_{\mathrm{m}} / Y_{\mathrm{g}}\right)$ at EOB would depend on the time of irradiation and the respective reaction cross sections, the number of the target nuclei and the projectile flux being common for the formation of the two products. Thus in the case of a reactor irradiation of $50 \mathrm{~h}$ duration, using the known thermal neutron capture cross sections for the ${ }^{185} \operatorname{Re}(n, \gamma){ }^{186 m, \mathrm{~g}} \mathrm{Re}$ processes, the ratio $\left(Y_{\mathrm{m}} / Y_{\mathrm{g}}\right)$ was calculated to be $1.8 \times 10^{-10}$. A similar calculation for a cyclotron irradiation of $50 \mathrm{~h}$ duration with $18 \mathrm{MeV}$ protons, using the calculated cross section ratio shown in Fig. 13, led to

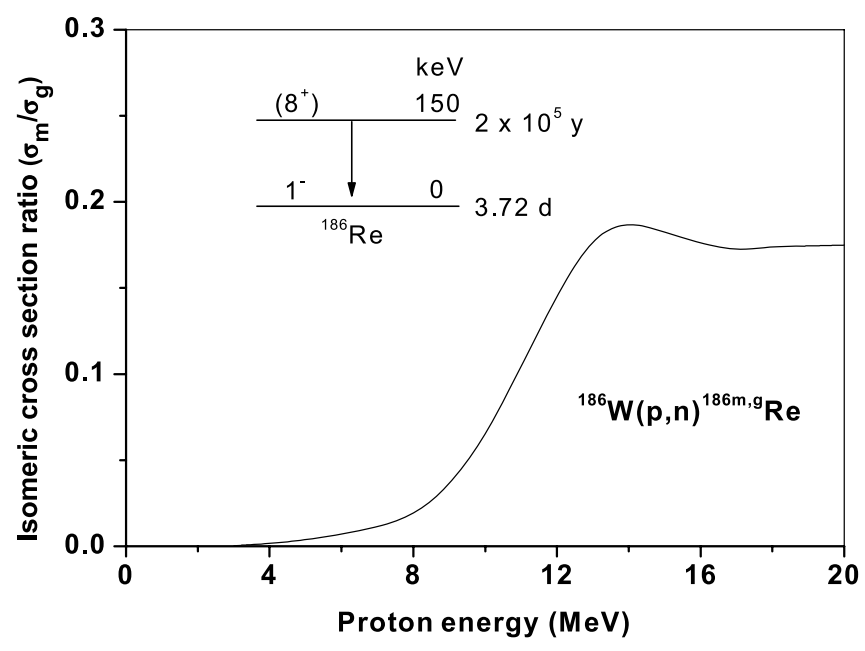

Fig. 13. Calculated isomeric cross section ratio $\left(\sigma_{\mathrm{m}} / \sigma_{\mathrm{g}}\right)$ for the ${ }^{186} \mathrm{~W}(p, n)^{186 \mathrm{~m}, \mathrm{~g}} \mathrm{Re}$ reaction by EMPIRE 3.0 , plotted as a function of proton energy.

a $\left(Y_{\mathrm{m}} / Y_{\mathrm{g}}\right)$ ratio of $1.08 \times 10^{-8}$. Thus in both reactor and cyclotron production, the amount of activity of ${ }^{186 \mathrm{~m}} \mathrm{Re}$ formed along with ${ }^{1869} \mathrm{Re}$ is negligibly small. However, if data are converted to number of nuclei, the ratio of ${ }^{186 \mathrm{~m}} \mathrm{Re}$ nuclei to ${ }^{186 g}$ Re nuclei would become $1.09 \times 10^{-3}$ and 0.211 for the above mentioned reactor and cyclotron irradiations, respectively. The latter will affect the specific activity of ${ }^{186 g} \mathrm{Re}$.

\section{Conclusion}

This work presents an evaluation of charged particle data available to date for the production of ${ }^{186} \mathrm{Re}$. Comprehensive and extensive nuclear model calculations using the codes STAPRE, EMPIRE and TALYS in support of the statistical fitting procedure led to the recommended sets of data which should be useful for optimizing the available routes for the production of the medical radionuclide ${ }^{186} \mathrm{Re}$ at accelerators or cyclotrons. Presently the ${ }^{186} \mathrm{~W}(p, n)^{186} \mathrm{Re}$ reaction using a highly enriched target is the method of choice for production of no-carrier-added ${ }^{186} \mathrm{Re}$.

Acknowledgment. This work has been performed under the PIN No. 041-211338-P-103, Higher Education Commission (HEC), Islamabad, Pakistan. M. Hussain gratefully acknowledges the hospitality of the Institute of Experimental Physics, University of Debrecen, Debrecen, Hungary. He also thanks the IAEA for supporting his participation in the Workshop on Nuclear Model Calculations (2008) in Vienna, Austria.

\section{References}

1. Hoefnagel, C. A.: Radionuclide therapy revisited. Eur. J. Nucl. Med. 18, 408-431 (1991)

2. Stöcklin, G., Qaim, S. M., Rösch, F.: The impact of radioactivity on medicine. Radiochim. Acta 70/71, 249-272 (1995).

3. Qaim, S. M.: Therapeutic radionuclides and nuclear data. Radiochim. Acta 89, 297-302 (2001).

4. Lewington, V. J.: Bone-seeking radionuclides for therapy. J. Nucl. Med. 46(Suppl. 1), 38S-47S (2005).

5. Bauman, G., Charette, M., Reid, R., Sathya, J.: Radiopharmaceuticals for the palliation of painful bone metastases - a systematic review. Radiother. Oncol. 75, 258.e1-258.e13 (2005).

6. Lam, M. G. E. H., Klerk, J. M. H., Rijk, P. P.: ${ }^{186}$ Re-HEDP for metastatic bone pain in breast cancer patients. Eur. J. Nucl. Med. Mol. Imaging 31(Suppl. 1), S162-S170 (2004). 
7. Syed, R., Bomanji, J., Nagabhushan, N., Kayani, I., Groves, A., Waddington, W., Cassoni, A., Ell, P. J.: ${ }^{186}$ Re-HEDP in the treatment of patients with inoperable osteosarcoma. J. Nucl. Med. 47, 1927-1935 (2006).

8. Moustapha, M. E., Ehrhardt, G. J., Smith, C. J., Szajek, L. P., Eckelman, W. C., Jurisson, S. S.: Preparation of cyclotron-produced ${ }^{186} \mathrm{Re}$ and comparison with reactor-produced ${ }^{186} \mathrm{Re}$ and generatorproduced ${ }^{188} \mathrm{Re}$ for the labeling of bombesin. Nucl. Med. Biol. 33, 81-89 (2006).

9. Qaim, S. M.: Use of cyclotrons in medicine. Radiat. Phys. Chem. 71, 917-926 (2004)

10. Capote, R., Bìták, E., Carlson, B. V., Choi, H. D., Ignatyuk, A., Menapace, E., Nortier, F. M., Qaim, S. M. (Chairman), Scholten, B. Shubin, Y. N., Sublet, J. C., Tárkányi, F. T.: 2008 IAEA coordinated research programme: nuclear data for the production of therapeutic radionuclides. (Bersillon, O., Gunsing, F., Bauge, E., Jacqmin, R., Leray, S., eds.) In: Proc. Int. Conf. Nucl. Data for Science and Technology, Nice, France, CEA, Paris (2007), pp. 13671370.

11. Qaim, S. M., Capote, R., Bìták, E., Carlson, B. V., Caldeira, A. D., Choi, H. D., Ignatyuk, A. V., Kiraly, B., Menapace, E., Nortier, F. M., Paviotti-Corcuera, R., Scholten, B. Shubin, Y. N., Sublet, J. C., Tárkányi, F. T.: Production of therapeutic radionuclides. IAEA-CRP (2010), data available from http://www-nds.iaea.org/ medportal/.

12. Tárkányi, F., Takács, S., Szelecsényi, F., Ditrói, F., Hermanne, A., Sonck, M.: Excitation functions of proton induced nuclear reactions on natural tungsten up to $34 \mathrm{MeV}$. Nucl. Instrum. Methods Phys. Res. B 252, 160-174 (2006).

13. Tárkányi, F., Takács, S., Szelecsényi, F., Ditrói, F., Hermanne, A., Sonck, M.: Excitation functions of deuteron induced nuclear reactions on natural tungsten up to $50 \mathrm{MeV}$. Nucl. Instrum. Methods Phys. Res. B 211, 319-330 (2003).

14. Szelecsényi, F., Takács, S., Tárkányi, F., Sonck, M., Hermanne, A.: Study of production possibility of no-carrier added ${ }^{186} \mathrm{Re}$ via proton induced reaction on tungsten for use in radiotherapy. (Heys, J. R., Melillo, D. G., eds.) In: Proc. $6^{\text {th }}$ Int. Symp. Synthesis and Applications of Isotopically Labelled Compounds, 14-18 September 1997, John Wiley \& Sons, Philadelphia, USA (1997), pp. 701-703.

15. Miyahara, H., Wurdiyanto, G., Nagata, H., Yoshida, A., Yanagida, K., Mori, C.: Precise measurements of the gamma-ray emission probabilities of ${ }^{186} \mathrm{Re}$ and ${ }^{188} \mathrm{Re}$. Appl. Radiat. Isot. 52, 573-579 (2000).

16. Shigeta, N., Matsuoka, H., Osa, A., Koizumi, M., Izumo, M., Kobayashi, K., Hashimoto, K., Sekine, T., Lambrecht, R. M.: Production method of no-carrier-added ${ }^{186}$ Re. J. Radioanal. Nucl. Chem. 205, 85-92 (1996).

17. Shigeta, I. N., Sekine, T., Lambrecht, R. M.: Comments on the cross sections of ${ }^{186} \mathrm{Re}$ in the ${ }^{186} \mathrm{~W}(p, n)$ and ${ }^{186} \mathrm{~W}(d, 2 n)$ reactions in connection to the paper given by Z. H. Zhu et al. and correction of the calculated yields of ${ }^{186} \mathrm{Re}$ in the ${ }^{186} \mathrm{~W}(p, n)$ reaction. J. Radioanal. Nucl. Chem. 241, 383 (1999).

18. Zhang, X., Li, W., Fang, K., He, W., Sheng, R., Ying, D., Hu, W.: Excitation functions for ${ }^{\text {nat }} \mathrm{W}(p, x n)^{181-186} \mathrm{Re}$ reactions and production of no-carrier-added ${ }^{186} \mathrm{Re}$ via ${ }^{186} \mathrm{~W}(p, n){ }^{186} \mathrm{Re}$ reaction. Radiochim. Acta 86, 11-16 (1999).

19. Miah, M. H., Kuhnhenn, J., Herpers, U., Michel, R., Kubik, P.: Production of residual nuclides by proton induced reactions on target $\mathrm{W}$ at an energy of $72 \mathrm{MeV}$. J. Nucl. Sc. Tech. Suppl. 2, 369-372 (2002).

20. Tárkányi, F., Hermanne, A., Takács, S., Ditrói, F., Kovalev, F., Ignatyuk, A. V.: New measurement and evaluation of excitation function of the ${ }^{186} \mathrm{~W}(p, n)$ nuclear reaction for production of the therapeutic radioisotope ${ }^{186} \mathrm{Re}$. Nucl. Instrum. Meth. Phys. Res. B 264, 389-394 (2007).

21. Lapi, S., Mills, W. J., Wilson, J., McQuarrie, S., Publicover, J., Schueller, M., Schlyer, D., Ressler, J. J., Ruth, T. J.: Production cross-sections of ${ }^{181-186} \mathrm{Re}$ isotopes from proton bombardment of natural tungsten. Appl. Radiat. Isot. 65, 345-349 (2007).

22. Menapace, E., Birattari, C., Bonardi, M. L., Groppi, F.: Experimental results and model calculations of excitation functions relevant to the production of specific radioisotopes for metabolic radiotherapy and for PET. Radiat. Phys. Chem. 71, 943-945 (2004).
23. Menapace, E., Bonardi, M. L., Groppi, F., Persico, E., Alfassi, Z. B.: Experimental and calculated nuclear reaction data relevant to innovative production of medical radioisotopes. (Bersillon, O., Gunsing, F., Bauge, E., Jacqmin, R., Leray, S., eds.) In: Proc. Int. Conf. Nucl. Data for Science and Technology, Nice, France, CEA, Paris (2007), pp. 1403-1406.

24. Khandaker, M. U., Uddin, M. S., Kim, K., Lee, M. W., Kim, K. S., Lee, Y. S., Kim, G. N., Cho, Y. S., Lee, Y. O.: Excitation functions of proton induced nuclear reactions on ${ }^{\text {nat }} \mathrm{W}$ up to $40 \mathrm{MeV}$. Nucl. Instrum. Methods Phys. Res. B 266, 1021-1029 (2008).

25. Pement, F. W., Wolke, R. L.: Compound-statistical features of deuteron induced reactions. Nucl. Phys. 86, 429-442 (1966).

26. Nassiff, S. J., Münzel, H.: Cross sections for the reactions ${ }^{66} \mathrm{Zn}(d, n)^{67} \mathrm{Ga},{ }^{52} \mathrm{Cr}(d, 2 n){ }^{52 \mathrm{~g}} \mathrm{Mn}$ and ${ }^{186} \mathrm{~W}(d, 2 n){ }^{186} \mathrm{Re}$. Radiochim. Acta 19, 97-99 (1973).

27. Zhenlan, T., Fuying, Z., Huiyuan, Q., Gongqing, W.: Excitation functions for ${ }^{182-186} \mathrm{~W}(d, 2 n)^{182-186} \mathrm{Re}$ and ${ }^{186} \mathrm{~W}(d, p)^{187} \mathrm{~W}$ reactions. Chin. J. Nucl. Phys. 3, 242-248 (1981).

28. Ishioka, N. S., Watanabe, S., Osa, A., Koizumi, M., Matsuoka, H., Sekine, T.: Excitation functions of rhenium isotopes on the ${ }^{\text {nat }} \mathrm{W}(d, x n)$ reactions and production of no-carrier added ${ }^{186} \mathrm{Re}$. J. Nucl. Sci. Tech. Suppl. 2, 1334-1337 (2002).

29. Szelecsényi, F., Takács, S., Tárkányi, F., Sonck, M., Hermanne, A.: Study of production possibility of ${ }^{186} \mathrm{Re}$ via the ${ }^{186} \mathrm{~W}(d, 2 n){ }^{186} \mathrm{Re}$ nuclear reaction for use in radiotherapy. J. Labelled Cpd. Radiopharm. 42(Suppl. 1), 912-914 (1999).

30. Alekseev, I. E., Lazarev, V. V.: Cyclotron production and radiochemical separation of medical therapeutical radionuclide ${ }^{186} \mathrm{Re}$. Sov. Radiochem. 48, 446-449 (2006).

31. Zhang, X., Li, Q., Li, W., Sheng, R., Shen, S.: Production of nocarrier-added ${ }^{186} \mathrm{Re}$ via deuteron induced reactions on isotopically enriched ${ }^{186} \mathrm{~W}$. Appl. Radiat. Isot. 54, 89-92 (2001).

32. Sudár, S., Cserpák, F., Qaim, S. M.: Measurements and nuclear model calculations on proton induced reactions on ${ }^{103} \mathrm{Rh}$ up to $40 \mathrm{MeV}$ : Evaluation of the excitation function of the ${ }^{103} \mathrm{Rh}(p, n){ }^{103} \mathrm{Pd}$ reaction relevant to the production of the therapeutic radionuclide ${ }^{103} \mathrm{Pd}$. Appl. Radiat. Isotopes 56, 821 (2002).

33. Hussain, M., Sudár, S., Aslam, M. N., Shah, H. A., Ahmad, R., Malik, A. A., Qaim, S. M.: A comprehensive evaluation of charged particle data for production of the therapeutic radionuclide ${ }^{103} \mathrm{Pd}$. Appl. Radiat. Isot. 67, 1842-1854 (2009).

34. Gul, K., Hermanne, A., Mustafa, M. G., Nortier, F. M., Obložinský, P., Qaim, S. M., (Chairman), Scholten, B., Shubin, Yu., Takács, S., Tárkányi, F., Zhuang, Y.: Charged Particle Cross Section Database for Medical Radioisotopes Production: Diagnostic Radioisotopes and Monitor Reactions. IAEA-TECDOC-1211 (2001), pp. 1-285.

35. Tagesen, S., Vonach, H., Wallner, A.: Evaluations of the fast neutron cross sections of ${ }^{182,183,184,186} \mathrm{~W}$ and ${ }^{181} \mathrm{Ta}$ including complete covariance information. Proc. International Conference on Nuclear Data for Science and Technology (2007), doi: 10.1051/ndata:07362.

36. Uhl, M., Strohmaier, B.: Computer code for particle induced activation cross section and related quantities. Institut für Radiumforschung and Kernphysik, Vienna, Report 76/01 and Addenda to this report (1976).

37. Sudár, S., Qaim, S. M.: Isomeric cross-section ratio for the formation of ${ }^{58 m, g} \mathrm{Co}$ in neutron, proton, deuteron and alpha-particle induced reactions in the energy region up to $25 \mathrm{MeV}$. Phys. Rev. C 53, 2885-2892 (1996).

38. Sudár, S., Qaim, S. M.: Cross sections for the formation of ${ }^{195 \mathrm{~m}, \mathrm{~g}} \mathrm{Hg},{ }^{197 \mathrm{~m}, \mathrm{~g}} \mathrm{Hg}$ and ${ }^{196 \mathrm{~m}, \mathrm{~g}} \mathrm{Au}$ in alpha and ${ }^{3} \mathrm{He}$-particle induced reactions on Pt: Effect of level density parameters on the calculated isomeric cross section ratio. Phys. Rev. C 73, 034613 (2006).

39. Bersillon, O.: SCAT 2: Un programme de modele optique spherique. Centre d'Etudes de Bruyéres-le-Châtel Report, CEA$\mathrm{N}-2227$ (1981).

40. Dilg, W., Schantl, W., Vonach, H., Uhl, M.: Level density parameters for the back-shifted Fermi gas model in the mass range $40<A<250$. Nucl. Phys. A 217, 269-298 (1973).

41. Belgya, T., Bersillon, O., Capote Noy, R., Fukahori, T., Zhigang, Ge., Goriely, S., Herman, M., Ignatyuk, A. V., Kailas, S., Koning, A. J., Obložinský, P., Plujko, V., Young, P. G.: Handbook 
for Calculations of Nuclear Reaction Data. RIPL-2, IAEATECDOC-1506 (2006), pp. 1-171.

42. Egidy, T. V., Bucurescu, D.: Systematics of nuclear level density parameters. Phys. Rev. C 72, 044311 (2005).

43. Tuli, J. K.: Nuclear Wallet Cards. National Nuclear Data Center, Brookhaven National Laboratory, USA (2005), pp. 1-115.

44. Herman, M., Capote, R., Carlson, B. V., Obložinský, P., Sin, M., Trkov, A., Wienke, H., Zerkin, V.: EMPIRE: Nuclear reaction model code system for data evaluation. Nucl. Data Sheets 108, 2655-2715 (2007).

45. Raynal, J.: ECIS code, distributed by the NEA Data Bank, Paris, France (2003).

46. Iwamoto, A., Harada, K.: Mechanism of cluster emission in nucleon induced preequilibrium reactions. Phys. Rev. C 26, 18211834 (1982).

47. Koning, A. J., Hilaire, S., Duijvestijn, M. C.: TALYS: Comprehensive nuclear reaction modeling. (Haight, R. C., Chadwick, M. B., Kawano, T., Talou, P., eds.) In: Proc. Int. Conf. Nucl. Data for Science and Technology, ND 2004, AIP vol. 769, 26 September1 October 2004, Santa Fe, USA (2004), pp. 1154-1159.

48. Koning, A. J., Delaroche, J. P.: Local and global nucleon optical models from $1 \mathrm{keV}$ to $200 \mathrm{MeV}$. Nucl. Phys. A 713, 231-310 (2003).
49. EXFOR Database: http://www-nds.iaea.org/exfor/exfor.htm.

50. Collé, R., Kishore, R., Cumming, J. B.: Excitation functions for $(p, n)$ reactions to $25 \mathrm{MeV}$ on ${ }^{63} \mathrm{Cu},{ }^{65} \mathrm{Cu}$ and ${ }^{107} \mathrm{Ag}$. Phys. Rev. C 9, 1819-1830 (1974).

51. Grütter, A.: Excitation functions for radioactive isotopes produced by proton bombardment of $\mathrm{Cu}$ and $\mathrm{Al}$ in the energy range of 16 to $70 \mathrm{MeV}$. Nucl. Phys. A 383, 98-108 (1982).

52. Steyn, G. F., Mills, S. J., Nortier, F. M., Simpson, B. R. S., Meyer, B. R.: Production of ${ }^{52} \mathrm{Fe}$ via proton-induced reactions on manganese and nickel. Appl. Radiat. Isot. 41, 315-325 (1990).

53. Dmitriev, P. P., Molin, G. A., Yields of ${ }^{181} \mathrm{Re},{ }^{182 \mathrm{~m}} \mathrm{Re},{ }^{182} \mathrm{Re},{ }^{183} \mathrm{Re}$, ${ }^{184 \mathrm{~m}} \mathrm{Re},{ }^{184} \mathrm{Re}$ and ${ }^{186} \mathrm{Re}$ when irradiating tungsten with protons and deuterons, and tantalum with alpha particles. Atom. Energ. 48, 122-124 (1980).

54. Alfassi, Z. B., Persico, E., Groppi, F., Bonardi, M. L., On the photon self-absorption correction for thin-target-yields $v s$. thicktarget-yields in radionuclide production. Appl. Radiat. Isot. 67, 240-242 (2009).

55. Solin, L., Jakovlev, V. A., Alekseev, I. E., Lazarev, V. V.: Cyclotron yields of rhenium-186. Proc. $5^{\text {th }}$ Int. Conf. on Isotopes, 25-29 April 2005, Brussels, Belgium, Medimond International Proceedings, (2005), pp. 131-136. 